\title{
Evaluating the Core Damage Frequency of a TRIGA Research Reactor Using Risk Assessment Tool Software
}

\author{
M. Nematollahi and Sh. Kamyab
}

\begin{abstract}
After all preventive and mitigative measures considered in the design of a nuclear reactor, the installation still represents a residual risk to the outside world. Probabilistic Safety Assessment is a powerful method to survey the safety of nuclear reactors. In this study the occurrence frequency of different types of core damage states (CDS) which may potentially arise in TRR is evaluated by use of the recently developed Risk Assessment Tool (RAT) software which has been designed and represented in the Safety Research Center of Shiraz University. RAT uses Event Trees and Fault Trees to evaluate the total final core damage frequency through studying the frequencies of initiation events, and following their consequences has resulted in one type of the CDS.

The criterion must be of the order of smaller than $10^{-4}$ through IAEA standards for research reactors. Results show that the total final CDF for TRR is of the order of $10^{-6}$, which meets the criterion of nuclear research reactor.
\end{abstract}

Index Terms - TRIGA Research Reactor, Core Damage Frequency, Risk Assessment Tool, PSA, Beta Factor Model.

\section{INTRODUCTION}

An initiating event is an event that creates a disturbance in the plant and has the potential to lead to core damage, depending on the successful operation of the various mitigating systems in the plant. For the purpose of this analysis, the list of initiating events (IEs) was determined through Engineering Evaluation, Operational Experience and reference to previous lists of similar reactors.

Once accident IEs have been identified and grouped, it is necessary to determine the response of the plant to each group of initiating events.

Event trees are graphic models that order and reflect events according to the requirements for mitigation of each group of initiating events. Events or 'headings' of an event tree can be a safety function's status, a system's status, basic events occurring or operator actions.

Fault tree analysis is the most common method used for representing the failure logic of plant systems. The fault tree itself is a graphic model of the various parallel and sequential combinations of faults that will result in the occurrence of the predefined undesired event.

In general, dependent failures are defined as events in

Manuscript received September 9, 2009.

Mohammadreza Nematollahi was with safety Center of Shiraz University, 71348-51154, Shiraz, Iran. He is no with department of Mechanical engineering, Shiraz University. Tel./fax:+987116473474 E-mail address: nema@shirazu.ac.ir

Shahabedin Kamyab is with the School of Engineering, Shiraz University 71348-51154, Shiraz, Iran. which the probability of each failure is dependent on the occurrence of other failures. In this case, the probabilities of dependent events are usually, but not always, greater than the corresponding independent probabilities.

The major causes of dependence among a set of systems or components can be explicitly described and modelled by system reliability analysis models such as fault trees. However, other causes can be collectively modelled using the concept of common cause failures (CCF). CCFs are considered the collection of all sources of dependencies (Intersystem, Intercomponent and External Dependencies), especially between components that are not known or are difficult to explicitly model in the system or component reliability analysis. CCFs have been shown by many reliability studies to contribute significantly to the overall unavailability or unreliability of complex systems.

Beta factor Model is one of the single parameter models that use just one parameter in addition to the total component failure probability to calculate the CCF probabilities. The sole parameter of the model $(\beta)$ can be associated with the fraction of the component failure rate that is due to common cause events shared by the other components in the system. That is,

Where: $\mathrm{B}=\lambda_{\mathrm{C}} /\left[\lambda_{\mathrm{C}}+\lambda_{\mathrm{I}}\right]=\lambda_{\mathrm{C}} / \lambda_{\mathrm{t}}$

$\lambda_{\mathrm{C}}=$ failure rate due to common cause failures

$\lambda_{\mathrm{I}}=$ failure rate due to independent failure

$\lambda_{\mathrm{t}}=\lambda_{\mathrm{C}}+\lambda_{\mathrm{I}}$

Having the $\beta$ value, we can use the expression of the multiple component failure frequency to calculate the required probabilities.

An important assumption of this model is that if a CCF shock strikes a redundant system, all components are assumed to fail immediately without any delays.

After calculating the common cause failure probabilities for redundant systems, they are added to fault trees logic to contribute to the overall probability.

\section{Methodology of Evaluation of CDF IN TEHRAN RESEARCH REACTOR:}

- Familiarization with the Plant and Information Gathering:

The 5 megawatt pool-type research reactor is a light-water moderated, heterogeneous, solid fuel reactor in which the water is also used for cooling and shielding. The reactor core is immersed in either section of a two-section concrete pool filled with water. One of the sections of the pool contains an experimental stall into which beam tubes and other experimental facilities converge. The other section is an open 
pool area for bulk irradiation studies. The pool is spanned by a manually operated bridge from which an aluminum tower that supports the reactor core is suspended. Control of the reactor is accomplished by the insertion or removal of neutron absorbing-control rods which are suspended from control-drives mounted on the Reactor Bridge. Additional control is provided by the inherent negative temperature coefficient of reactivity of the system.

The core has been fuelled with Low Enriched Uranium (LEU) elements of U3O8-Al type. The fuel enrichment is approximately $20 \%$ in weight of U-235. The equilibrium LEU core contains 23 standard fuel elements and 5 control fuel elements. Each standard fuel element consists of 19 flat plates inserted in two grooved side plates (lateral walls). The control fuel element is of the same size as the standard fuel element but consists of only 14 fuel plates to accommodate the fork type control rods.

Initiation Events Identification: Only internal IEs, i.e. hardware failures in the plant or faulty operations of plant hardware through human error or computer software deficiencies have been considered. Two major categories of IEs can be distinguished.

Loss of Coolant Accident initiator (LOCA) is an event that directly causes loss of integrity of the primary coolant pressure boundary. Transient initiators are those that could create the need for a reactor power reduction or shutdown and subsequent removal of decay heat.

Based on the response of the safety systems we have considered 11 groups of initiating events, of which four are LOCA initiators and the others are Transient initiators. Transient initiators are also subdivided to the following categories:

Loss of Offsite Power Supply (LOPS)

Loss of Flow, Forced Circulation Unavailable (LFFCU)

Loss of Flow, Forced Circulation Available (LFFCA)

Excess Reactivity Insertion (ERI)

As mentioned earlier, the next step after identification of IEs is to construct an Event tree which traces the following consequences (to final state which may be a CDS) associated with the performance of safety function systems.

Core Damage States: Core damage has been conservatively assumed to occur when the available thermo-hydraulic models cannot support successful cool-down of the reactor core, given a particular state for the various safety systems. More detailed calculations might indicate that in some cases core damage is not actually occurring. All accident sequences identified do not lead to the same degree of core damage. Depending on the initiating event, the safety systems that operate and on the indications of the thermo-hydraulic analysis, eight states have been defined, of which two are just abnormal states (do not lead to core damage) and the others are core damage states. These eight states are described below:

- CDS1: When the reactor shutdown takes place successfully but the natural circulation system fails (with no primary heat removal).

- CDS2: When the reactor fails to shutdown and there is no primary heat removal.

- CDS3: When the reactor fails to shutdown in the case of fuel channel blockage accident.
- CDS4: When the reactor does not shutdown in the case of reactivity accident, although the primary heat removal system works normally.

- CDS5: When the reactor does not shutdown in the case of a reactivity accident and the primary heat removal system also fails.

- CDS6: When the reactor shutdown takes place but the core is bared because of failure of the pool isolation system in the case of LOCA.

- CDS7: When the reactor shutdown does not take place but the core is bared because of failure of the pool isolation system in the case of LOCA.

- CDS8: When the reactor shutdown does not take place and both NC and FC systems work normally but because of opening of the safety flapper the core is bypassed.

The data required for quantification of the models that yield the frequency of initiating events are the numbers of occurrences of the events and the total periods over which these events have been observed.

After definition and selection of initiating events, the frequency of occurrence of these events must be quantified. We consider that the frequency of initiating events is constant, i.e. that the events occur randomly in time, and that the distribution of times between occurrences is exponential. The parameter to be estimated therefore is the intensity $\lambda$ of this process. Specific accident sequences are defined that consist of an initiating event group, specific system failures and successes and possible human responses. The system failures are in turn modelled in terms of basic event component unavailability and human error to identify their basic causes and to allow for the quantification of the system failure probabilities (unavailability) and accident sequence frequencies. Table 1 represents the probability results for an example data set of basic events which has been used in IEs frequency evaluation.

Dependent failures are considered by the use of $\beta$ model. It should be noted that although $\beta$ model can be used with some degree of accuracy for two component redundancy, the results tend to be conservative for a higher level of redundancy. Since in this research reactor the highest level of redundancy is two out of three components, and considering lack of data for dependent events, this model is the best selection to generate common cause failure probabilities.

To evaluate the final probability of each branch of an Event Tree which results in a specific probability of radioactive release, each stage must be quantified. This means that the probability of each stage must be calculated as the top event of associated fault tree by the aid of a logical combination of basic events through logic gates.

\section{RESULTS AND DISCUSSION}

For evaluating the final CDF, appropriated event trees associated with different initiating failures should be constructed. The development of event trees is due to safety systems which are considered to function in the occurrence of an initiating event. Figures 1 and 2 show two Event Trees which are constructed for two IEs. 
Proceedings of the International MultiConference of Engineers and Computer Scientists 2010 Vol III, IMECS 2010, March 17 - 19, 2010, Hong Kong

Evaluating the frequency of occurrence of initiation events has been done through appropriate fault trees. A RAT modelled fault tree is represented in Figure 3 as an example. The output of a fault tree is the failure probability of corresponding IE occurrence. After developing such fault trees, the frequency of 11 types of initiation events is given in Table 2.

As mentioned earlier, CCF probability is evaluated by the use of $\beta$-factor model. However, generally speaking, this model can be used with some degree of accuracy for two component redundancy; the results tend to be conservative for a higher level of redundancy. Since in this research reactor the highest level of redundancy is two out of three components and considering lack of data for dependent events, this model is the best selection to generate common cause failure probabilities. In some cases where there is not enough dependent failures data, it is possible to use generic databases that contain the generic values of $\beta$. When there is enough data available we use the simple point estimators to calculate the $\beta$.

The $\beta$ is considered 0.15 through experts' opinions. Table 3 shows the frequency of different sorts of CCFs in TRR.

It should be noted that the CCF probability of shut down system scram rods is just calculated for the event of 'failure of 2 scram rods to drop', because the failure probability of the event 'failure of 5 scram rods to drop' is extracted from the generic databases.

The final core damage states (CDS) and their corresponding frequencies are reported in Table 4.

It is seen that the CDS3 and CDS8 have the highest frequency among others. The accident initiators of these two states are the 'fuel channel blockage' and 'spurious opening of the flapper accident'.

Since the failure of scram rods and corresponding electromagnets are the most important contributors to frequency of total core damage, altering the shape of scram rods is very important to decrease this contribution. The other solution can be to test the electromagnet system of these rods to find the optimum electrical current that, in the case of a scram condition there is no residual electromagnetic field to prohibit the scram rods from dropping.

Another major contributor to core damage of this reactor is the deficiency of detecting a foreign object in the core. The related CDS3 also has the highest frequency among others. Using online video camera imaging, instrumental fuel elements or instruments to detect the pressure difference in the fuel channel is very helpful to decrease the frequency of this state of core damage.

After all, it should be noticed that since two of the CDS do not tend to significant damages, which are CDS1 and CDS6, the frequencies of the six core damage states are just considered in total core damage frequency.

\section{FIGURES AND TABLES}

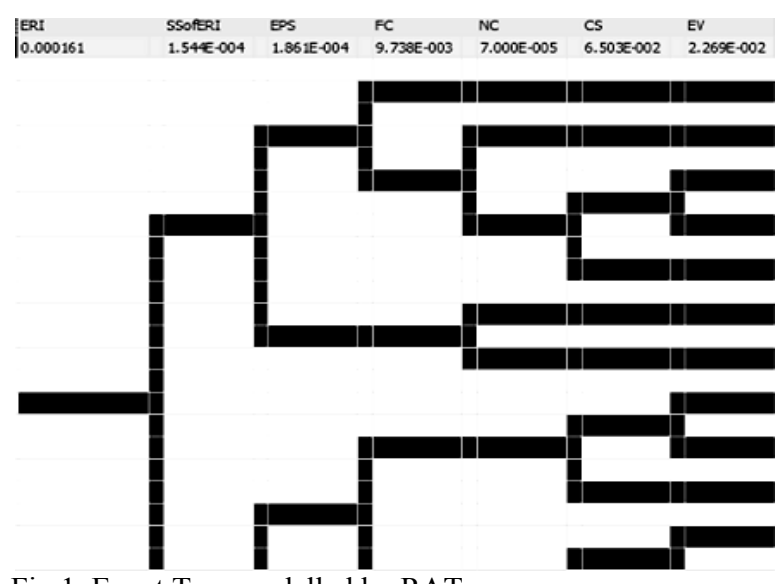

Fig 1. Event Tree modelled by RAT

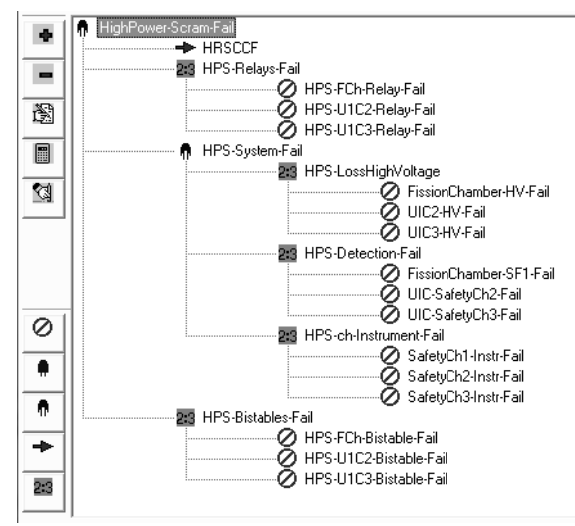

Fig 2. Fault Tree modelled by RAT

Table I. Basic Event Failure Probability

\begin{tabular}{|c|c|c|c|}
\hline 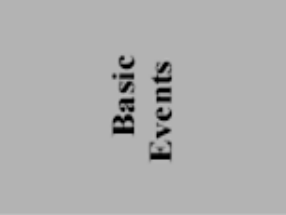 & 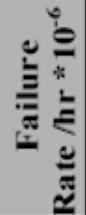 & 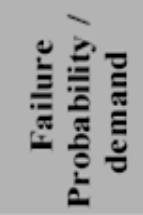 & 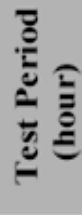 \\
\hline 2 Scram Rods F2Drop & 64.4 & $1.525 \mathrm{E}-4$ & 336 \\
\hline 4 Scram Rods F2Drop & $\ldots$ & $2.28 \mathrm{E}-6$ & $\ldots$ \\
\hline Core Replace Fail & 10 & $1.072 \mathrm{E}-2$ & 2160 \\
\hline CS-Valve-V1-F2Close & 7.1 & $7.629 \mathrm{E}-3$ & 2160 \\
\hline CS-Valve-V2-F2Close & 7.1 & $7.629 \mathrm{E}-3$ & 2160 \\
\hline CS-Valve-V3- F2Close & 7.1 & $7.629 \mathrm{E}-3$ & 2160 \\
\hline CS-Valve-V4- F2Close & 7.1 & $7.629 \mathrm{E}-3$ & 2160 \\
\hline CS-Valves- Relays Fail & 33.2 & $3.501 \mathrm{E}-2$ & 2160 \\
\hline EV-Fan- E1C-F2Run & 27 & $2.860 \mathrm{E}-2$ & 2160 \\
\hline EV-Fan- E1C-F2Start & 1.5 & $1.618 \mathrm{E}-3$ & 2160 \\
\hline EV-Fan- E1D-F2Run & 27 & $2.860 \mathrm{E}-2$ & 2160 \\
\hline EV-Fan-E1D-F2Start & 1.5 & $1.618 \mathrm{E}-3$ & 2160 \\
\hline EV-Filters-Fail & 4.1 & $4.415 \mathrm{E}-3$ & 2160 \\
\hline EV-Relay-Fail & 8.3 & 8.911E-3 & 2160 \\
\hline EV-Valve A-F2Open & 7.1 & $7.629 \mathrm{E}-3$ & 2160 \\
\hline EV-Valve B-F2Open & 7.1 & $7.629 \mathrm{E}-3$ & 2160 \\
\hline EV-Valve V5-F2Open & 7.1 & $7.629 \mathrm{E}-3$ & 2160 \\
\hline Fission Chamber-HV-Fail & 16.6 & $1.660 \mathrm{E}-4$ & 0 \\
\hline Fission Chamber-SF1-Fail & 53 & $5.299 \mathrm{E}-4$ & 0 \\
\hline
\end{tabular}


Proceedings of the International MultiConference of Engineers and Computer Scientists 2010 Vol III, IMECS 2010, March 17 - 19, 2010, Hong Kong

Table II. Initiating events Frequency

\begin{tabular}{|c|c|c|}
\hline IE Group & Accident Type & Frequency/hr \\
\hline LOPS & Power Disconnection & $1.19 \mathrm{E}-2$ \\
\hline LFFCU1 & $\begin{array}{l}\text { Primary Pump Fail (Except } \\
\text { Electrical) } \\
\text { Valve Failure After Hold up } \\
\text { Tank } \\
\text { Piping Blockage After Hold } \\
\text { up Tank }\end{array}$ & $\begin{array}{l}4.70 \mathrm{E}-4 \\
2.338 \mathrm{E}-5 \\
1.88 \mathrm{E}-4 \\
6.813 \mathrm{E}-4\end{array}$ \\
\hline LFFCU2 & $\begin{array}{l}\text { Primary Pump Fail (Electric } \\
\text { Failure) }\end{array}$ & $7.50 \mathrm{E}-4$ \\
\hline LFFCA1 & Fuel Channel Blockage & $2.74 \mathrm{E}-5$ \\
\hline LFFCA2 & Spurious Opening of Flapper & $2.57 \mathrm{E}-4$ \\
\hline LFFCA3 & $\begin{array}{l}\text { Pool Outlet Valve Erroneous } \\
\text { Closing } \\
\text { Piping Blockage Before Hold } \\
\text { up Tank }\end{array}$ & $\begin{array}{l}5.00 \mathrm{E}-6 \\
3.76 \mathrm{E}-5 \\
4.260 \mathrm{E}-5\end{array}$ \\
\hline ERI & $\begin{array}{l}\text { Beam Tubes Flooding } \\
\text { Experiments } \\
\text { SFE Drop } \\
\text { CFE Drop (Stuck Rod) } \\
\text { Control Rod \& Drive System } \\
\text { Fail }\end{array}$ & $\begin{array}{l}3.22 \mathrm{E}-5 \\
3.22 \mathrm{E}-5 \\
--- \\
6.44 \mathrm{E}-5 \\
3.22 \mathrm{E}-5 \\
1.610 \mathrm{E}-4\end{array}$ \\
\hline LOCA1 & $\begin{array}{l}\text { Beam Tubes Rupture } \\
\text { Pool Wall Sheared (Liner } \\
\text { Break) }\end{array}$ & $\begin{array}{l}\text { 6.85E-6 } \\
----\end{array}$ \\
\hline LOCA2 & $\begin{array}{l}\text { Primary Cooling Piping } \\
\text { Break }\end{array}$ & $4.2 \mathrm{E}-5$ \\
\hline LOCA3 & $\begin{array}{l}\text { Break Between Pool \& Inlet } \\
\text { Valve }\end{array}$ & $1.42 \mathrm{E}-5$ \\
\hline LOCA4 & $\begin{array}{l}\text { Break Between Pool \& Outlet } \\
\text { Valve }\end{array}$ & $1.42 \mathrm{E}-5$ \\
\hline
\end{tabular}

Table III. CCFs Probability

\begin{tabular}{l|l|l} 
CCF Component & Beta & Probability \\
\hline $\begin{array}{l}\text { Emergency Ventilation } \\
\text { System(FANS) }\end{array}$ & 0.15 & $4.542 \mathrm{E}-3$ \\
\hline $\begin{array}{l}\text { High Power Scram System- } \\
\text { BISTABLES }\end{array}$ & 0.15 & $5.516 \mathrm{E}-7$ \\
\hline $\begin{array}{l}\text { High Power Scram System- } \\
\text { DETECTORS }\end{array}$ & 0.15 & $9.919 \mathrm{E}-11$ \\
\hline $\begin{array}{l}\text { High Power Scram System- } \\
\text { HIGH VOLTAGE }\end{array}$ & 0.15 & $1.587 \mathrm{E}-9$ \\
\hline $\begin{array}{l}\text { High Power Scram System- Ch. } \\
\text { INSTRUMENT }\end{array}$ & 0.15 & $5.990 \mathrm{E}-6$ \\
\hline $\begin{array}{l}\text { High Power Scram System- } \\
\text { RELAYS }\end{array}$ & 0.15 & $7.613 \mathrm{E}-6$ \\
\hline $\begin{array}{l}\text { High Radiation Scram System- } \\
\text { DETECTORS }\end{array}$ & 0.15 & $9.00 \mathrm{E}-6$ \\
\hline $\begin{array}{l}\text { High Radiation Scram System- } \\
\text { RELAYS }\end{array}$ & 0.15 & $2.00 \mathrm{E}-4$ \\
\hline $\begin{array}{l}\text { High Radiation Scram System- } \\
\text { BISTABLES }\end{array}$ & 0.15 & $5.59 \mathrm{E}-5$ \\
\hline \begin{tabular}{l} 
Shutdown System Scram Rods \\
\hline
\end{tabular} & 0.15 & $1.525 \mathrm{E}-4$
\end{tabular}

Table IV. CDS Frequencies (Descending Order)

\begin{tabular}{c|c} 
Core Damage States & $\begin{array}{c}\text { Frequency Per } \\
\text { Operation Year }\end{array}$ \\
\hline CDS3 & $6.797 \mathrm{E}-6$ \\
\hline CDS8 & $1.438 \mathrm{E}-6$ \\
\hline CDS4 & $1.047 \mathrm{E}-7$ \\
\hline CDS2 & $2.758 \mathrm{E}-8$ \\
\hline CDS5 & $1.038 \mathrm{E}-9$ \\
\hline CDS7 & $1.706 \mathrm{E}-10$ \\
\hline Total & $8.638 \mathrm{E}-6$
\end{tabular}

\section{CONCLUSION}

Results which have been obtained for CCFs show that dependent failure has a significant effect on CDF. Therefore, in some cases neglecting them would cause misleading results that may be absolutely smaller than the real results.

This level 1 PSA performed for TRR indicates, based on conservative assumptions that the total frequency of accidents that would lead to core damage from internal initiating events, is $8.368 \mathrm{E}-6$ per year of reactor operation.

It is possible to make the CDF less than the current quantity after making some changes which must be designed in the plant composition and safety systems to improve their functions in the procedure of accident mitigation, as mentioned in the result and discussion section; as an example, the shape of the control rods and the mechanism of electromagnets.

Furthermore, the accident procedures of LOCA initiators must be well practiced by the operators to decrease the human error corresponding to these accidents which in turn will decrease the CDF.

The probabilistic safety criteria of IAEA for power reactors level 1 result is assigned a frequency of one core damage event in 10,000 years of plant operation for existing plants $\left(10^{-4}\right.$ per reactor operating year). Therefore, after everything mentioned above the core damage frequency of the Tehran Research Reactor (8.368E-6) is approximately 12 times lower than the acceptance criteria of IAEA for existing plants.

This frequency is not expected to significantly change, even when external events such as earthquake and fire risk are added because of the low frequency of occurrence of these events. It seems that this result meets the IAEA criterion.

\section{ABBREVIATIONS AND ACRONYMS}

$\begin{array}{lll}\text { CDF } & : & \text { Core Damage Frequency } \\ \text { CDS } & : & \text { Core Damage State } \\ \text { ERI } & : & \text { Excess Reactivity Insertion } \\ \text { FC } & : & \text { Forced Circulation } \\ \text { LFFCA } & : & \text { Loss of Flow Force Recirculation Available } \\ \text { LFFCU } & : & \text { Loss of Flow Force Recirculation Unavailable } \\ \text { LOCA } & : & \text { Loss of Coolant Accident } \\ \text { LOPS } & : & \text { Loss of Offsite Power Supply } \\ \text { NC } & : & \text { Natural Circulation } \\ \text { PSA } & : & \text { Probabilistic Safety Assessment } \\ \text { RAT } & : & \text { Risk Assessment Tool } \\ \text { SRC } & : & \text { Safety Research Center } \\ \text { TRR } & : & \text { TRIGA Research Reactor }\end{array}$


Proceedings of the International MultiConference of Engineers and Computer Scientists 2010 Vol III, IMECS 2010, March 17 - 19, 2010, Hong Kong

\section{REFERENCES}

[1] IAEA-TECDOC-400, Probabilistic Safety Assessment for Research Reactors, International Atomic Energy Agency, Vienna, 1986

[2] M. Modarres, What Every Engineer Should Know about Reliability and Risk Analysis, Marcel Decker, New York, 1993

[3] M. Modarres, Risk Analysis In Engineering, Taylor \& Francis, 2006

[4] A. Majdara, Design and Implementation of a Risk Monitor and its Application for a Typical Research Reactor, M.Sc.Thesis in Nuclear Engineering, 2006

[5] A. Majdara and M.R. Nematollahi, Development and Application of Risk Assessment, Reliability Engineering \& Systems Safety, 93, 1130-1137, 2008

[6] NUREG-0492, Fault Tree Handbook, U.S. Nuclear Regulatory Commission, Washington DC, USA, 1981

[7] M.Hosseini, Probabilistic Safety Assessment Of Tehran Research Reactor , M.Sc.Thesis in Nuclear Engineering, 2003 